Correction

\title{
Correction: The Nrf2 inhibitor brusatol is a potent antitumour agent in an orthotopic mouse model of colorectal cancer
}

\author{
Jonathan P. Evans ${ }^{1, *}$, Boleslaw K. Winiarski ${ }^{2,}{ }^{*}$, Paul A. Sutton ${ }^{1}$, Robert P. Jones ${ }^{1}$, \\ Lorenzo Ressel ${ }^{3}$, Carrie A. Duckworth ${ }^{4}$, D. Mark Pritchard ${ }^{4}$, Zhi-Xiu Lin ${ }^{5}$, Vicky L. \\ Fretwell $^{1}$, Elizabeth M. Tweedle ${ }^{1}$, Eithne Costello ${ }^{1}$, Christopher E. Goldring ${ }^{2}$, Ian \\ M. Copple ${ }^{2}$, B. Kevin Park ${ }^{2}$, Daniel H. Palmer ${ }^{1,6}$ and Neil R. Kitteringham² \\ ${ }^{1}$ Department of Molecular and Clinical Cancer Medicine, Institute of Translational Medicine, University of Liverpool, Liverpool, \\ United Kingdom \\ ${ }^{2}$ MRC Centre for Drug Safety Science, Department of Molecular and Clinical Pharmacology, Institute of Translational Medicine, \\ University of Liverpool, Liverpool, United Kingdom \\ ${ }^{3}$ Department of Veterinary Pathology, Institute of Veterinary Science, University of Liverpool, Liverpool, United Kingdom \\ ${ }^{4}$ Department of Cellular and Molecular Physiology, Institute of Translational Medicine, University of Liverpool, Liverpool, \\ United Kingdom \\ ${ }^{5}$ School of Chinese Medicine, Faculty of Medicine, The Chinese University of Hong Kong, Hong Kong, People's Republic of \\ China \\ ${ }^{6}$ Clatterbridge Cancer Centre, Liverpool, United Kingdom \\ * Joint first authorship \\ Published: January 18, 2019
}

Copyright: Evans et al. This is an open-access article distributed under the terms of the Creative Commons Attribution License 3.0 (CC BY 3.0), which permits unrestricted use, distribution, and reproduction in any medium, provided the original author and source are credited.

This article has been corrected: The correct Author name is given below:

\section{Vicky L. Fretwell}

Original article: Oncotarget. 2018; 9:27104-27116. https://doi.org/10.18632/oncotarget.25497 